Research Article

\title{
A Comparative Study of Wind Tunnel Tests and Design Codes in Evaluation of Along-Wind Effects on Towers
}

\author{
Seungho Lee $\mathbb{D}^{1},{ }^{1}$ Sooyong Kim, ${ }^{2}$ and Soon-Duck Kwon $\mathbb{D i D}^{1}$ \\ ${ }^{1}$ KOCED Wind Tunnel Center, Department of Civil Engineering, Jeonbuk (Chonbuk) National University, Jeonju, \\ Jeonbuk 54896, Republic of Korea \\ ${ }^{2}$ Department of Regional Development, Jeonbuk Institute, Jeonju, Jeonbuk 55068, Republic of Korea \\ Correspondence should be addressed to Soon-Duck Kwon; sdkwon@jbnu.ac.kr
}

Received 30 April 2020; Revised 21 December 2020; Accepted 4 February 2021; Published 19 February 2021

Academic Editor: Tzu-Kang Lin

Copyright (c) 2021 Seungho Lee et al. This is an open access article distributed under the Creative Commons Attribution License, which permits unrestricted use, distribution, and reproduction in any medium, provided the original work is properly cited.

\begin{abstract}
This study aims to estimate the wind loads acting on a tower structure by comparing and reviewing design codes and the results of wind tunnel tests. To this end, the modal properties of the tower were identified through short-term on-site measurements of the Busan Tower in Korea. The wind load acting on the tower was calculated using four design codes: KBC2009 (Korea), ASCE7-10 (USA), EUROCODE (Europe), and AIJ2004 (Japan). Additionally, force measurement tests and aeroelastic model tests were conducted for comparison. The results obtained indicated that the design wind velocity of each design code differed slightly, reflecting the individual characteristics of each country. The base shear force, base moment, and maximum displacement obtained from each design code were similar to those obtained in the wind tunnel tests. The magnitudes of the base moments and maximum displacements calculated by each design code were in the order of $\mathrm{KBC}>\mathrm{AIJ} \approx \mathrm{EUROCODE}>\mathrm{ASCE}$. The overall results indicate that each design code reasonably estimates the wind forces and the responses of the tower and also has an appropriate safety margin. The scatter in the predicted wind loads occurs primarily from the variations in the design wind velocity in the respective design codes.
\end{abstract}

\section{Introduction}

Recent global trends emphasize the significance and importance of city tourism, leading numerous cities to build observation towers. However, as the slenderness of the towers increase, they become highly vulnerable to dynamic horizontal loads, such as wind loads. This leads to serviceability issues for the residents of such structures. The vibration generated by strong winds is a crucial factor for structural design and serviceability. Design codes provide accurate stochastic procedures for calculating wind loads and their effects on structures. Each design code is developed in different ways reflecting the situation and environment of each country. However, it is natural for engineers to wonder how different it will be if they apply a different design code from that of their country when designing a structure. Furthermore, engineers may be curious about how similar the wind load calculated using the design code is to that obtained from wind tunnel tests. The differences and similarities in the estimates, based on design codes, are important for engineers.

Jesien et al. [1] conducted a comparative study of four methods of calculating the wind response of buildings: the National Building Code (NBC) of Canada, the American Society of Civil Engineers (ASCE) 7-88 of USA, the state-ofthe-art procedures by Solari [2] and Simiu [3], and Engineering Science Data Unit (ESDU). Satisfactory agreement between the methods was found for calculated forces and mean displacements. However, discrepancies in the resonant component of displacements and accelerations were identified because of different wind velocity spectra and pressure correlation functions. Lungu et al. [4] compared the meteorological, structural, and aerodynamical data used for calculating wind loads in the EUROCODE, ISO 4354, and ASCE 7-95 codes. They, however, simply compared the data and did not draw any conclusions. 
Kijewski and Kareem [5] compared the building responses predicted by wind tunnel data and the data estimated by the building codes of USA, Japan, Australia, UK, Canada, China, and Europe. Estimates from AIJ and ASCE7-95 were highly congruent for along-wind acceleration measured in the wind tunnel, while the Australian code matched across-wind acceleration. Zhou et al. [6] compared the along-wind loads on buildings using the international codes ASCE 7-98 of USA, AS1170.2-89 of Australia, NBC1995 of Canada, AIJ-1993 of Japan, and EUROCODE-1993 of Europe. They considered the definition of wind characteristics, mean wind loads, gust loading factor (GLF), equivalent static wind loads, and attendant wind load effects. They found that the scatter in the predicted wind loads arose from variations in the definition of wind field characteristics in the respective codes.

Kwon and Kareem [7] examined the differences and similarities in the wind loads and their effects on buildings based on the international codes ASCE 2010 (USA), AS/NZ 2011 (Australia and New Zealand), AIJ 2004 (Japan), CNS 2012 (China), NBCC 2010 (Canada), EUROCODE 2010 (Europe), ISO 2009, and IWC 2012 (India). They found that the overall loads were reasonably consistent in the alongwind response, whereas more scatter was observed in the across-wind response. Badri et al. [8] conducted a comparative study of different codes including the Egyptian code, ECP 201-08, ASCE 7-05, and BS 6399-2, along with wind tunnel test results. The overall design wind loads obtained from the wind tunnels were generally lower than those estimated by the codes. Additionally, Holmes et al. [9] and Bashor and Kareem [10] also compared design codes.

This study was conducted to compare design codes and wind tunnel test results for estimating the wind loads acting on a tower structure, whereas previous studies compared only the values computed by applying each design code; in this study, wind tunnel test results were compared in addition to the calculated values of each code. Thus, in this study, it was possible to compare absolutely how close the calculated results of each code are to the experimental values. An aeroelastic model test and force measurement test of an existing tower in Korea were conducted to measure the aerodynamic forces and dynamic displacements. The wind tunnel test results were compared with the shear force and bending moment calculated based on major design codes from various countries. Additionally, through structural analysis, the wind loads, calculated by these codes, were applied to the tower structure to obtain the maximum displacement, which was then compared with the aeroelastic model test results. The design codes compared and reviewed were EUROCODE (Europe) [11], ASCE7-10 (USA) [12], AIJ2004 (Japan) [13], and KBC2009 (Korea) [14].

\section{Modal Properties of the Tower}

2.1. Target Structure. The Busan Tower, considered in this study, is located in Yongdusan Park, Busan, Korea. As shown in Figure 1, the Busan Tower is a concrete observation tower symbolizing Busan and is located on a hill, $69 \mathrm{~m}$ above sea level. It is $120 \mathrm{~m}$ high and has a column diameter of
6.80-6.44 m. An observatory in the shape of an octagonal pagoda is installed at the top of the tower. The Busan Tower was completed in 1973. There is no sensor in the tower to tell if any vibration has occurred. However, there have been no reports of wind-induced vibrations, including vortex shedding, having been observed in the tower for the past 47 years. Because of urbanization, the surrounding environment has changed from that at the time of construction, along with the structural design standards. Therefore, its aerodynamic stability must be reviewed, considering the current wind environment and latest design standards. As the across-wind and torsional vibrations are not a problem in this tower, the scope of this study was limited to the alongwind vibration.

2.2. Short-Term Measurements. To assess the response of a structure through wind tunnel tests, accurate information on the dynamic properties of the target structure is required. For this purpose, short-term observations were taken. The accelerometer PIEZOTRONICS 393B04 (PCB), which is suitable for seismic measurement in low frequency, was used for the measurement. The frequency band of the accelerometer is $0.06-450 \mathrm{~Hz}$, and its sensitivity is $1 \mathrm{~V} / \mathrm{g}$. The acceleration signals were collected using NI 9234 DAQ.

Figure 2 is a photo showing field measurements being conducted. The measurements were taken at the outer roof on top of the observatory. The north-south and east-west directions were distinguished for measuring the acceleration. Here, the ambient vibration acceleration of the tower due to weak winds was measured. Three rounds of shortterm field measurements were conducted during which the sampling frequency was changed to $20 \mathrm{~Hz}$ and $100 \mathrm{~Hz}$. Additionally, time history acceleration of at least 100 minutes was collected in each direction during measurement. A $10 \mathrm{~Hz}$ low-pass filter was applied to eliminate high-frequency noise from the measured data. Figure 3 shows the measured time history accelerations.

\subsection{Identified Natural Frequencies and Damping Ratios.} Frequency domain decomposition (FDD) was used to analyze the acceleration signals measured at the Busan Tower. As FDD is an output-only system identification method, it is suitable for analyzing ambient vibration signals $[15,16]$. The peak picking method and the zero-crossing count method were used to identify the natural frequencies of the tower. A natural frequency of $0.242 \mathrm{~Hz}$ was identified for the first mode, $1.648 \mathrm{~Hz}$ for the second mode, and $4.395 \mathrm{~Hz}$ for the third mode.

Owing to weak winds when measuring the acceleration at the Busan Tower, it was judged that aerodynamic damping would not have a large impact. Thus, the measured acceleration data were judged to satisfy the conditions of ambient vibration and white noise, which are basic assumptions of the system identification method. A data length of $2^{16}$ in the frequency domain was used when calculating the damping ratio through FDD. Additionally, the half-power bandwidth method and the logarithmic decrement method were used to estimate the damping ratio. Figure 4 shows the process of 


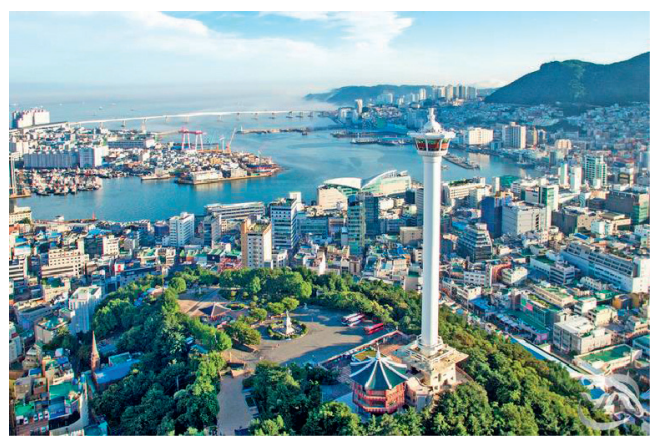

Figure 1: Busan tower.

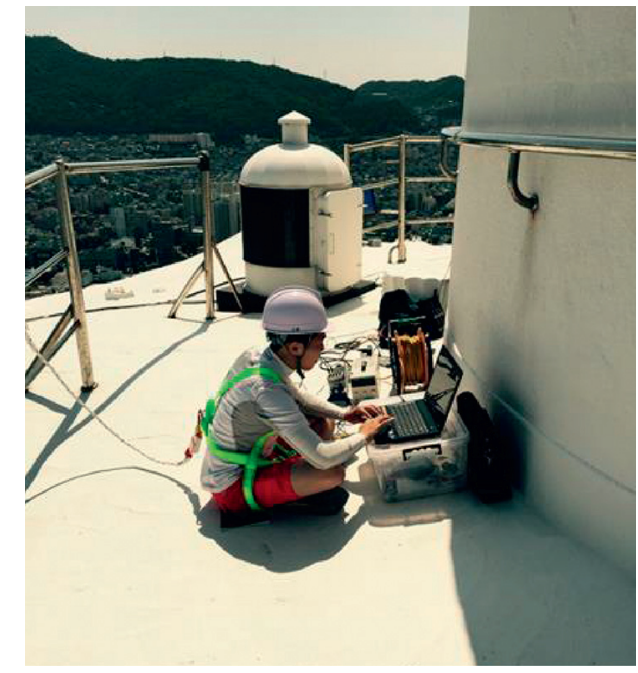

FIGURE 2: Field measurement of ambient vibrations.

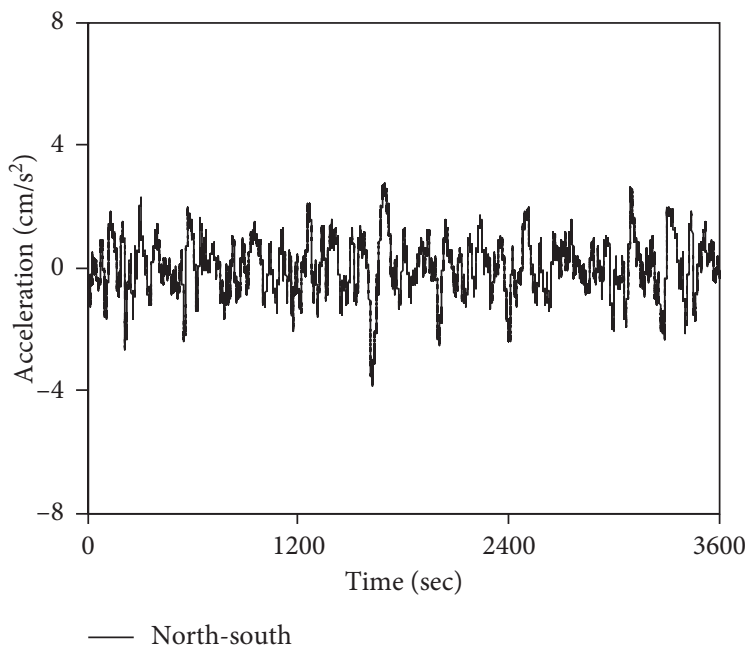

(a)

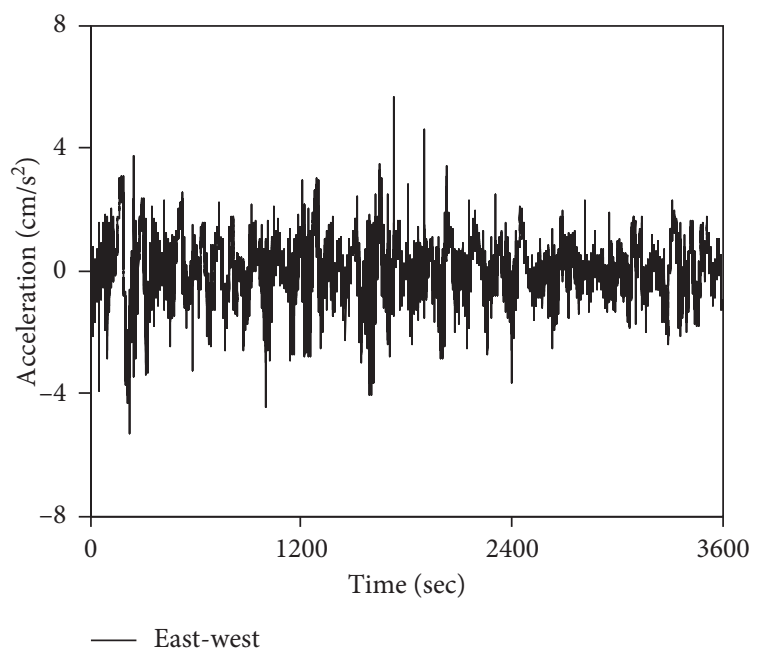

(b)

Figure 3: Measured time history accelerations. (a) North-south direction. (b) East-west direction.

using FDD to identify the natural frequency and damping ratio of the first mode. Table 1 shows the natural frequencies and damping ratios of the Busan Tower, ultimately obtained by the system identification method.
2.4. Computed Natural Frequencies. This study compared the natural frequencies obtained from field measurements with those calculated from structural analysis to confirm the validity of the analysis model for further study. The 


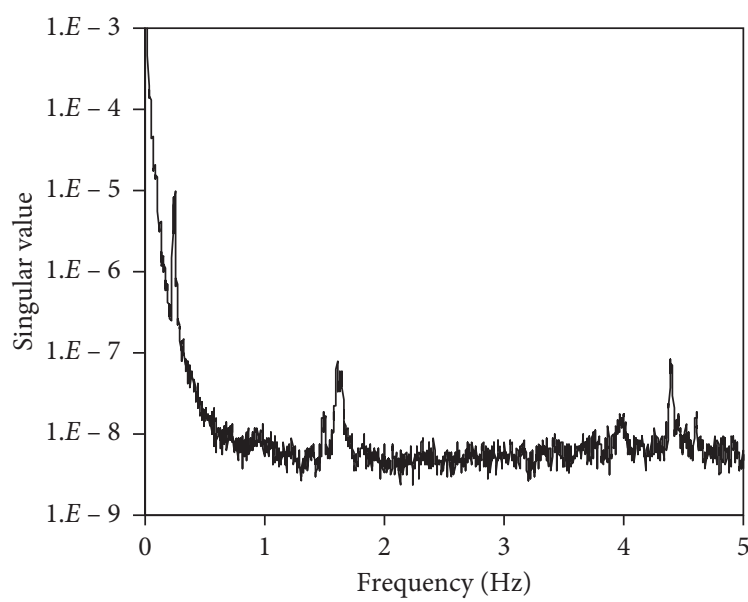

a)

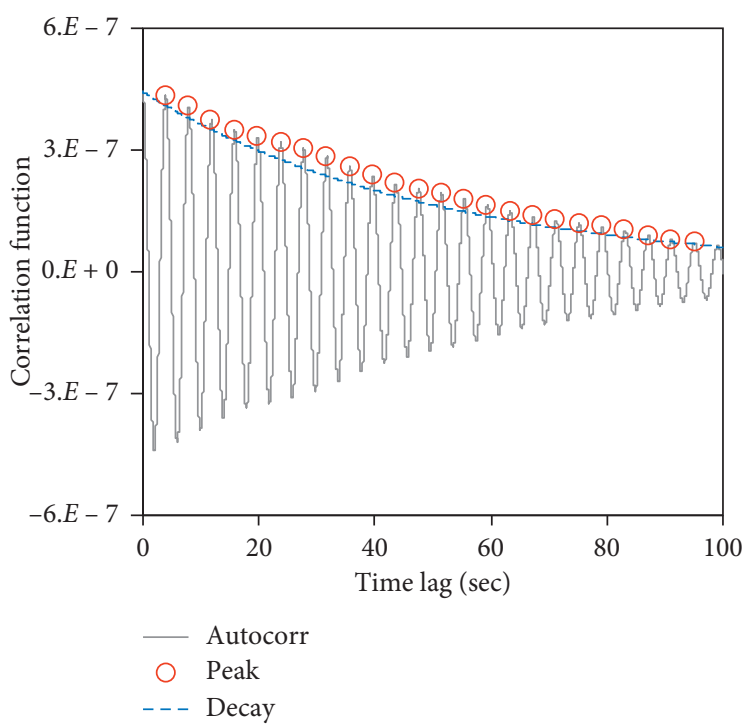

(b)

FIGURE 4: Identification of natural frequency and damping ratio from frequency domain decomposition (FDD) method. (a) Singular value. (b) Correlation function.

TABle 1: Modal properties of the Busan tower.

\begin{tabular}{lcccc}
\hline \multirow{2}{*}{ Mode } & \multicolumn{2}{c}{ Natural frequency (Hz) } & \multicolumn{2}{c}{ Measured damping ratio (\%) } \\
& Measured & ANSYS & MIDAS & \\
\hline 1 & 0.242 & 0.253 & 0.248 & 1.0 \\
2 & 1.648 & 1.636 & 1.642 & 1.7 \\
3 & 4.395 & 3.919 & 4.239 & - \\
\hline
\end{tabular}

commercial software applications ANSYS [17] and MIDAS [18] were used for free vibration analysis. In the structural analysis, solid elements were used in ANSYS and frame elements were used in MIDAS. Figure 5 shows the structural analysis models. As shown in Table 1, the natural frequencies obtained from the structural analysis highly coincided with the measurements. These structural analysis models were used to obtain the wind-induced responses of the tower.

\section{Wind Tunnel Tests}

3.1. Experimental Setup. The wind tunnel tests were carried out at KOCED Wind Tunnel Center in Jeonbuk (Chonbuk) National University, Korea. This experiment is using equipment connected by Korea Research Environment Open Network (KREONET). The high-speed test section in this closed-circuit wind tunnel was $5.0 \mathrm{~m}$ wide, $2.5 \mathrm{~m}$ high, $20 \mathrm{~m}$ long, and the maximum wind velocity was $31 \mathrm{~m} / \mathrm{s}$. The turbulent intensities were less than $0.6 \%$ at $5 \mathrm{~m} / \mathrm{s}$. The wind tunnel was equipped with a heat exchanger to prevent sudden changes in air temperature.

The free stream velocity was measured using two pitot tubes and pressure transducers (Setra 239). A Vinotech GHP-20R sensor was used to monitor the temperature and humidity changes during measurements. The aerodynamic forces acting on the model were measured using a JR3 force balance that could read three forces and the associated three moments. In the preliminary test, the external balance was checked by applying a static load on the tower model in three directions. The correction for the blockage effect was not done because of a lower blockage ratio than $5 \%$.

For the turbulence in the wind tunnel, this study simulated a wind velocity profile with a roughness exponent of 0.15 , corresponding to flat open terrain [19]. The turbulent flow was modeled in the wind tunnel by an array of five spires and roughness blocks placed at the flow inlet. A Dantec CTA-90C10 constant temperature anemometer incorporated with Dantec 55P11 hotwire sensor was used to measure the turbulent wind velocity. Figure 6 shows the turbulence characteristics at each height, measured in the test section and converted to actual structure height.

3.2. Aerodynamic Force Measurement. Force balance tests were performed to measure the static wind loads acting on the tower under uniform wind flow with low turbulent intensity. The aerodynamic force acting on a tower's circular column is well-researched. However, as the Busan tower's octagonal observatory has a unique geometry, the aerodynamic force is unknown. Accordingly, in this study, we constructed a 1/60 scale rigid model, as shown in Figure 7, to measure the aerodynamic force acting only on the tower's observatory. The bottom column in the model is a dummy for reproducing the three-dimensional wind flow.

The roof of the observatory is octagonal, while the viewing windows are circular, influenced by the Reynolds number. In a preliminary test, to assess the effect of the Reynolds number on the aerodynamic force, the aerodynamic force was measured at different wind velocities. As shown in Figure 8, the aerodynamic forces $\left(C F_{x}, C F_{y}\right)$ and moments $\left(C M_{x}, C M_{y}, C M_{z}\right)$, excluding the lift coefficient $\left(C F_{z}\right)$, are not greatly affected by the Reynolds number as the wind velocity exceeds $6 \mathrm{~m} / \mathrm{s}$. The lift force does not impact 


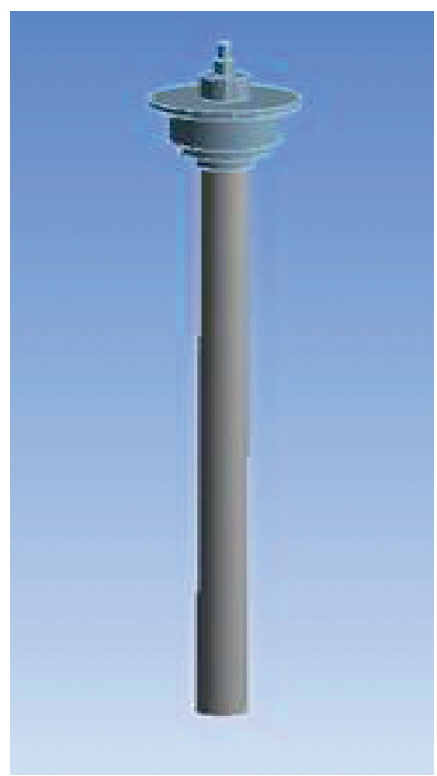

(a)

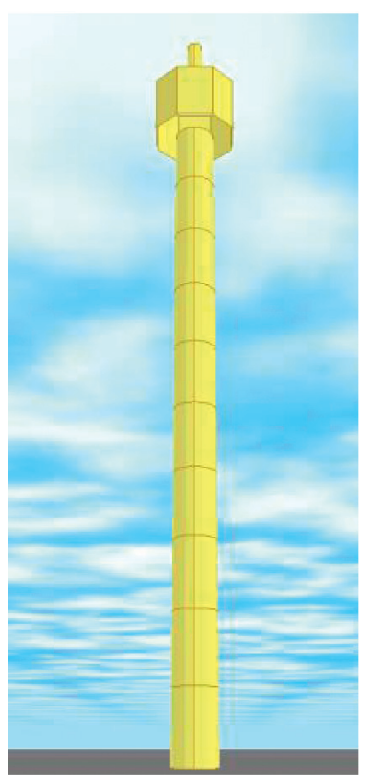

(b)

Figure 5: Structural analysis model. (a) ANSYS. (b) MIDAS.

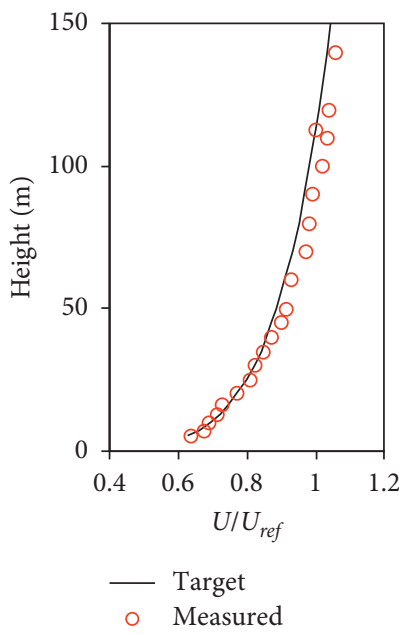

(a)

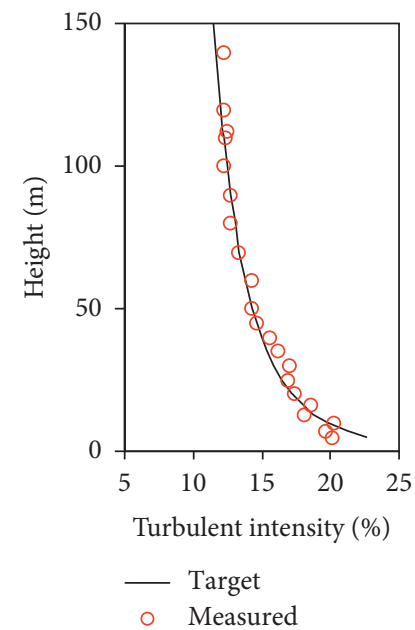

(b)

Figure 6: Boundary layer wind profile in the test section. (a) Mean wind velocity. (b) Turbulent intensity.

the lateral vibration at the tower. Moreover, in the case of a concrete tower with heavy self-weight, the lift force has a negligible impact on the tower response. Considering these, a wind velocity of $11 \mathrm{~m} / \mathrm{s}$ for the wind tunnel was determined to measure the aerodynamic forces.

The wind azimuth angles were divided into 5-degree intervals from 0 to 60 degrees for the octagon-shaped observatory roof. Figure 9 shows the aerodynamic force coefficients according to the wind direction. As the effect of the octagonal roof on the aerodynamic forces was not significant, the drag coefficient was nearly constant, regardless of the wind angle. The side force coefficient was close to zero. The measured drag coefficient showed a maximum value of 0.602 and an average value of 0.579 .
3.3. Aeroelastic Model Test. Considering the height of the tower and the surrounding topography, the scale of the model was decided at $1 / 200$. The Reynolds numbers of the tower range from $5 \times 10^{6}$ to $3 \times 10^{7}$ in natural wind, whereas those of the scaled model were $3 \times 10^{3}$ to $2 \times 10^{4}$ in the wind tunnel. Artificial surface roughness can create flow features past the circular cylinder model similar to that of high Reynolds numbers and then achieve an equivalent effect of high Reynolds number [20-23]. In this study, the outer surface of the model was covered with P100 sandpaper, which has a similar ratio of surface roughness and diameter to that of Liang et al. [22]. Figure 10 shows the original model and the model with sandpaper in the wind tunnel. The measured drag coefficient of the model with sandpaper was 


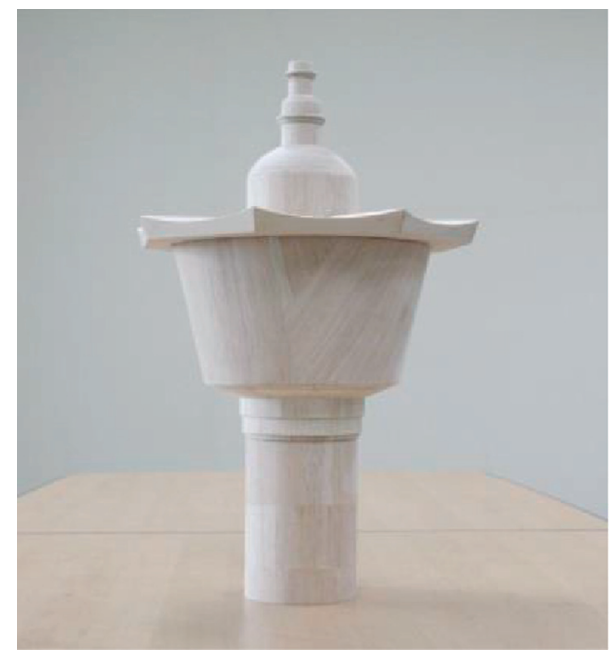

Figure 7: Rigid tower observatory model (1:60 scale).

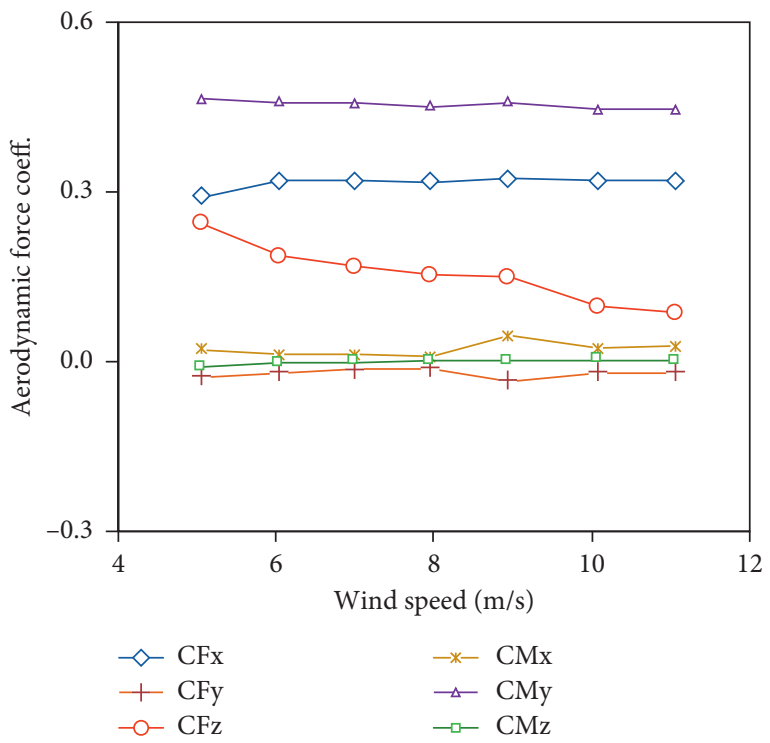

Figure 8: Reynolds number dependence of aerodynamic forces acting on the tower observatory.

0.58 at a Reynolds number of $2 \times 10^{4}$, which showed that increasing the surface roughness had a high Reynolds number simulation effect. The measured drag coefficient of the original model was similarly 0.55 at the same Reynolds number. This was because the surface roughness of the original model made of balsa wood was similar to that of sandpaper. As the original model without sandpaper also had the equivalent effect of high Reynolds number, the main vibration test was conducted with the original model.

A 1:200 scale aeroelastic model was constructed to measure the vibration of the tower. As shown in Figure 11, the terrain and buildings within a $600 \mathrm{~m}$ diameter of the Busan Tower were originally simulated. It is known that if the surrounding terrain is complex, then multiple factors affect tower vibration. When comparing design codes, it is

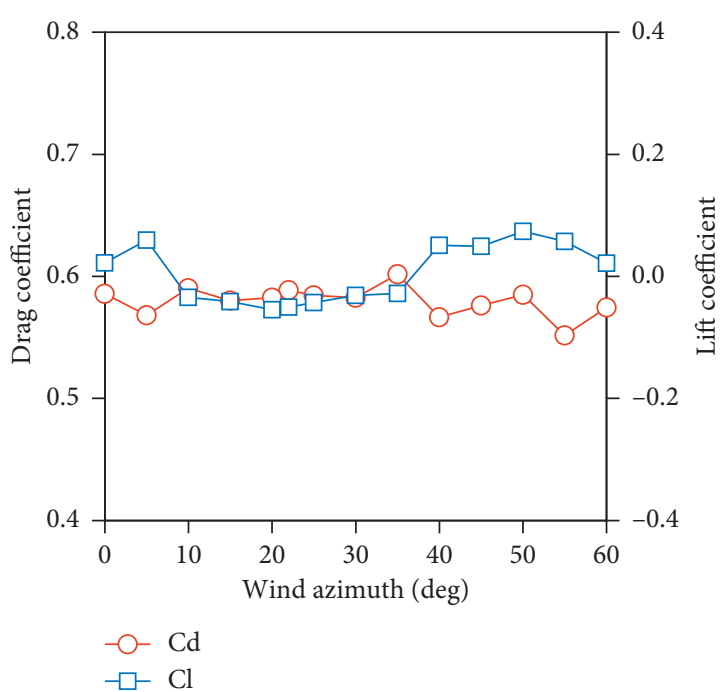

Figure 9: Drag and lift coefficients of the observatory.

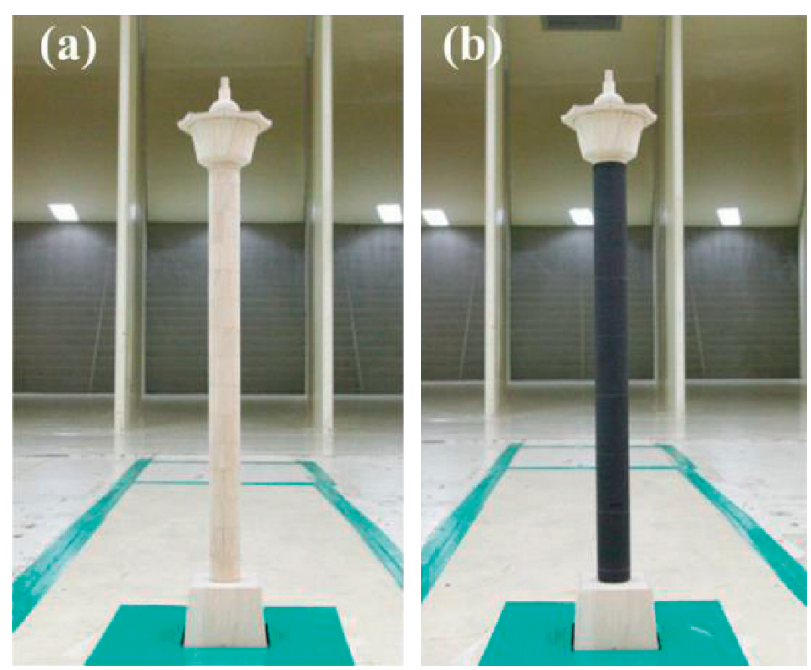

Figure 10: Wind tunnel models: (a) original model; (b) model with sandpaper.

advantageous to consider simple conditions. Therefore, in this study, the surrounding terrain model was removed, and a flat open area condition was simulated.

The Froude number similitude law was applied to simulate the dynamic properties of the aeroelastic model. As the geometric scale of the model was $1: 200$, the scales of wind velocity and time were, respectively, $\sqrt{200}$ and $1 / \sqrt{200}$. The flexural rigidities of the tower were reproduced using a metal spine, and the outer blocks were made of wood. The outer blocks were spaced $1 \mathrm{~mm}$ apart to reduce the impact on rigidity and damping. Table 2 shows the structural properties of the aeroelastic model used in the wind tunnel tests. The first mode natural frequency of the model was measured at $3.52 \mathrm{~Hz}$, similar to the target value of $3.42 \mathrm{~Hz}$ according to the similarity law. The first mode damping ratio of the model was very low, at $0.25 \%$. Rubber tapes were attached to the model to increase the damping ratio to $1.08 \%$, similar to the target value. A pair of noncontact 


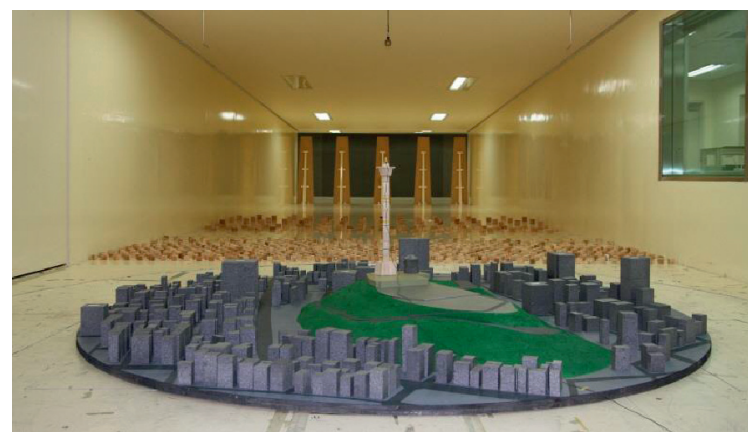

Figure 11: Full aeroelastic model test of the Busan tower $(1: 200$ scale).

TAble 2: Properties of the aeroelastic model (1:200 scale).

\begin{tabular}{|c|c|c|c|c|}
\hline \multirow{2}{*}{ Parameter } & & \multirow{2}{*}{$\begin{array}{c}\text { Prototype } \\
(\mathrm{Hz})\end{array}$} & \multicolumn{2}{|c|}{ Model } \\
\hline & & & Target $(\mathrm{Hz})$ & Measured $(\mathrm{Hz})$ \\
\hline \multirow{2}{*}{$\begin{array}{l}\text { Natural } \\
\text { frequency }\end{array}$} & $1^{\text {st }}$ & 0.242 & 3.42 & 3.52 \\
\hline & $2^{\text {nd }}$ & 1.648 & 23.3 & 24.1 \\
\hline \multirow{2}{*}{ Damping ratio } & $1^{\text {st }}$ & $1.0 \%$ & $1.0 \%$ & $1.08 \%$ \\
\hline & $2^{\text {nd }}$ & $1.7 \%$ & $1.7 \%$ & - \\
\hline
\end{tabular}

optical displacement transducers, Hamamatsu C5949, was used to measure the dynamic displacement of the tower in the along-wind and across-wind directions.

Figure 12 shows the measured along-wind displacements at the tower top according to the wind velocity. No vortex shedding was observed on the tower, and only buffeting response caused by turbulence was recorded. The average peak factor dividing the peak dynamic displacement by root mean square (rms) displacement was approximately 3.6. The gust effect factor-the ratio of the maximum displacement to the static displacement-ranged from 3.7 to 2.5 and decreased as the wind velocity increased.

3.4. Equivalent Static Wind Forces. The equivalent static wind force approach presents wind loading data in the form of an effective static load distribution corresponding to the maximum response [24-26]. This approach extracts design loads from the aeroelastic model test results by expressing the dynamic loads in terms of the equivalent static loads. The equivalent static force representation is formulated in terms of the weighted combination of modal properties and inertial load components.

In this study, the equivalent static wind force was calculated according to the method proposed by Holmes [26]. The equivalent static wind force was obtained by using the dynamic displacement at the tower top. First, the influence line for the tower top was calculated. Then, after multiplying the mode shape, mass, and influence, it was integrated with respect to the height to obtain the integral coefficient. The weighting factors for each mode were then calculated using the integral coefficient, natural frequencies, and measured displacement at the tower top. Subsequently, the total equivalent static wind force was obtained by multiplying the mode shape by the weighting factor for each mode.
Figure 13 shows the along-wind equivalent wind force acting on the tower, obtained from the aeroelastic model test. The equivalent wind force was computed for a condition where the maximum displacement of $0.388 \mathrm{~m}$ occurred when a basic wind velocity of $40 \mathrm{~m} / \mathrm{s}$ was applied at $10 \mathrm{~m}$ above the ground. The equivalent static wind force and the corresponding shear force and moment are compared with the values calculated based on design codes in Section 4 .

\section{Comparison of Wind Tunnel Test and Design Codes}

Four design codes-EUROCODE-2010 (Europe), ASCE710 (USA), AIJ-2004 (Japan), and KBC2009 (Korea)-were used to compare the wind-induced response of the Busan tower. The basic wind velocity, the 10 minutes mean wind velocity at the height of $10 \mathrm{~m}$, was set to $40 \mathrm{~m} / \mathrm{s}$ in order to compare responses. Additionally, the terrain surrounding the tower was assumed to be flat open terrain.

4.1. Wind Velocities. The KBC, EUROCODE, and AIJ use the 10-minute mean wind velocity. The basic wind velocity employed by ASCE, which uses a $3 \mathrm{~s}$ gust, was converted to $55.2 \mathrm{~m} / \mathrm{s}$ using the Durst Curve. Figure 14 and Table 3 show the wind velocities for the four design codes. KBC, ASCE7, and AIJ employ the exponential law to express the vertical profile of the wind velocity according to the surface roughness, whereas EUROCODE uses the logarithmic law. The wind velocities at specific heights were calculated by multiplying the basic wind velocity by a height correction factor. In terms of the height correction factors, in order to obtain the wind velocity at $120 \mathrm{~m}$ (the height of the Busan tower), those referred to from the KBC, EUROCODE, and AIJ design codes were similar, while ASCE7 differed. The former codes all use the 10-minute average, while ASCE7 uses a three-second average.

The KBC2009 multiplies an importance factor of 1.1 when calculating the design wind velocity of the tower. The importance factor varies with the building risk category, depending on the use or occupancy of the structures. In $\mathrm{KBC} 2009$, the height of the structure is also a parameter that determines the importance factor.

4.2. Gust Effect Factors. The gust effect factor is defined as the ratio of the maximum response to the mean response of a structure $[27,28]$. The gust effect factor varies with the rigidity and geometry of the structure. When calculating the gust effect factor, the lowest natural frequency of $1 \mathrm{~Hz}$ is often used to classify rigid or flexible structures. The Busan tower has a first natural frequency of $0.242 \mathrm{~Hz}$; hence, it is classified as a flexible structure. Table 3 compares the gust effect factor for each design code at the height of $120 \mathrm{~m}$. The gust effect factor lies in the range of 2.40 to 2.65, excluding the ASCE design code. The ASCE7 differs from others because of the different average time periods of the wind velocity. 


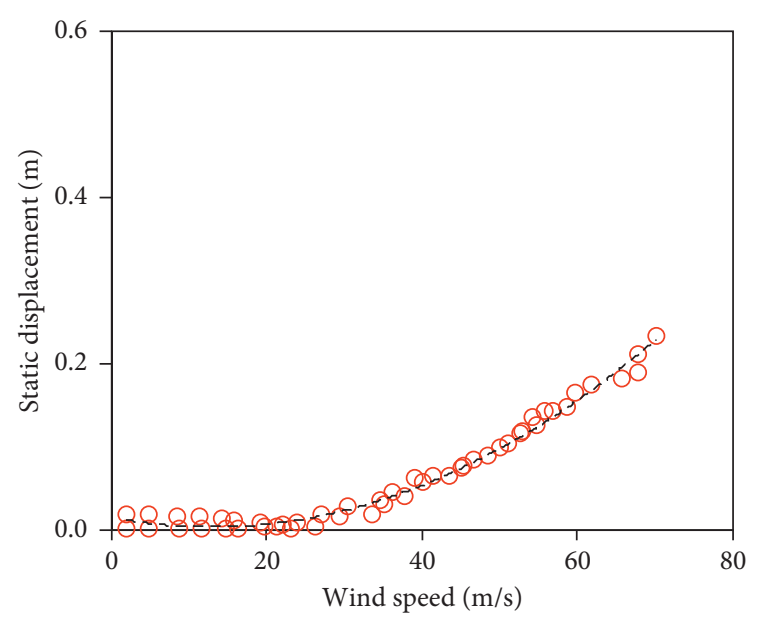

○ Measured

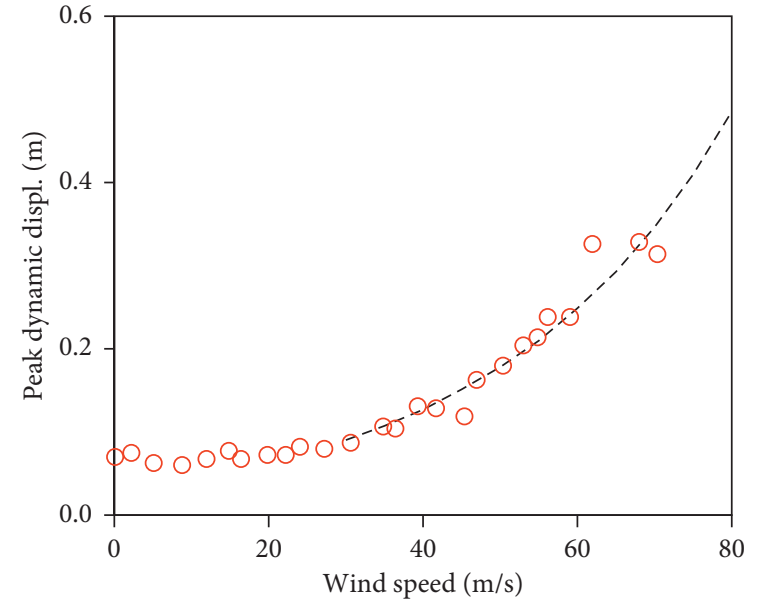

○ Measured

- - - Best-fit

(a)

(b)

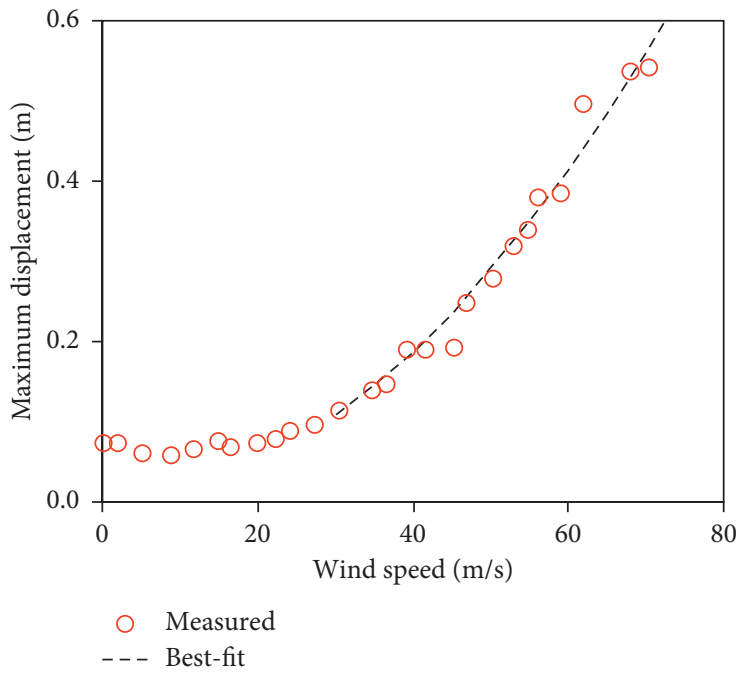

(c)

Figure 12: Along-wind displacements at tower top. (a) Static displacement. (b) Peak dynamic displacement. (c) Maximum displacement.

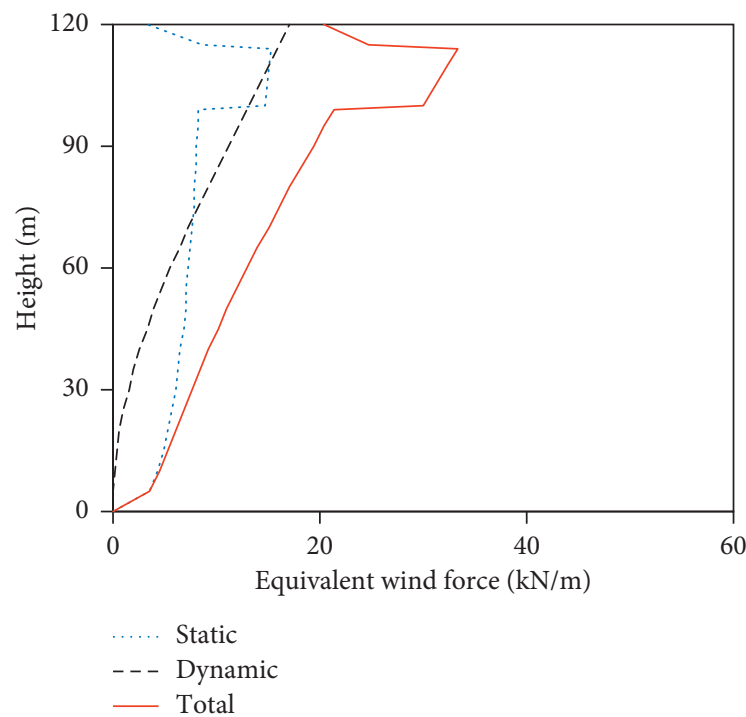

FIGURE 13: Along-wind equivalent wind forces evaluated from the aeroelastic model test. 


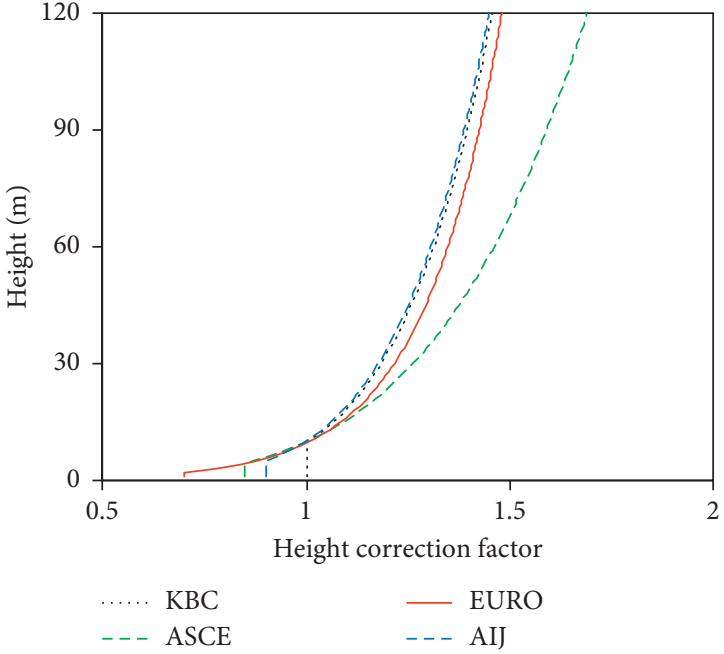

(a)

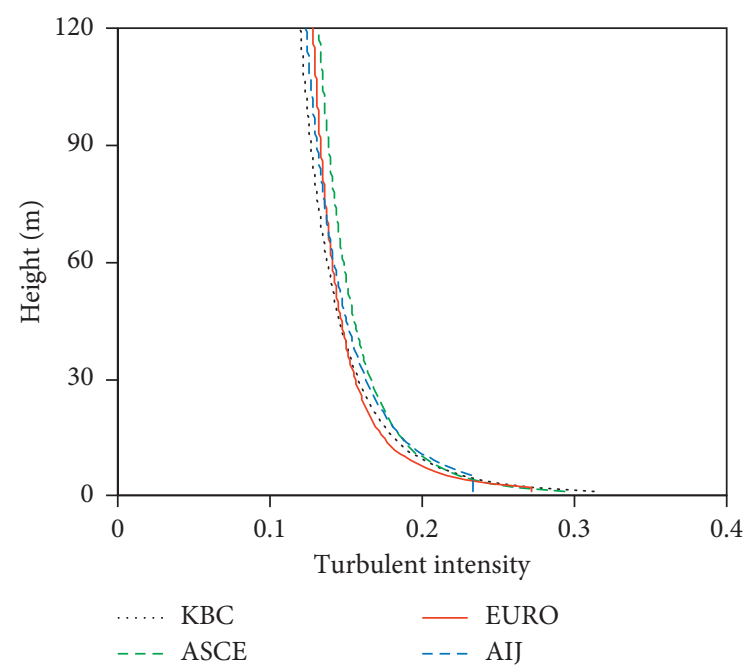

(b)

Figure 14: Vertical profile of wind velocities and turbulent intensities on flat open terrain. (a) Height correction factor. (b) Turbulent intensity.

TABLE 3: Wind velocities and gust effect factors.

\begin{tabular}{|c|c|c|c|c|}
\hline Parameter & $\mathrm{KBC}$ & ASCE & EUROCODE & AIJ \\
\hline Average time & $10 \mathrm{~min}$ & $3 \mathrm{~s}$ & $10 \mathrm{~min}$ & $10 \min$ \\
\hline Basic wind velocity at $10 \mathrm{~m}$ & $40 \mathrm{~m} / \mathrm{s}$ & $55.2 \mathrm{~m} / \mathrm{s}$ & $40 \mathrm{~m} / \mathrm{s}$ & $40 \mathrm{~m} / \mathrm{s}$ \\
\hline Height correction factor at $120 \mathrm{~m}$ & 1.456 & 1.689 & 1.479 & 1.448 \\
\hline Wind velocity at $120 \mathrm{~m}$ & $64.1 \mathrm{~m} / \mathrm{s}$ & $71.7 \mathrm{~m} / \mathrm{s}$ & $59.2 \mathrm{~m} / \mathrm{s}$ & $57.9 \mathrm{~m} / \mathrm{s}$ \\
\hline Turbulent intensity at $120 \mathrm{~m}$ & 0.120 & 0.132 & 0.128 & 0.124 \\
\hline Gust effect factor (rigid) & 1.756 & 0.855 & 1.899 & - \\
\hline Gust effect factor (flexible) & 2.412 & 1.370 & 2.651 & 2.402 \\
\hline
\end{tabular}

4.3. Along-Wind Forces. Figure 15 compares the wind force according to each design code and the equivalent static wind force in Section 3.4. The method of calculating the wind velocity at the height of $120 \mathrm{~m}$, at the top of the tower, was according to each design code. Among the wind tunnel test results, the maximum displacement corresponding to the wind velocity of $40 \mathrm{~m} / \mathrm{s}$ at $10 \mathrm{~m}$ above ground was chosen to compute the equivalent static wind forces. The wind velocity profile in the wind tunnel was converted to a real structure using the exponential law $(\alpha=0.15)$. The equivalent static force was then calculated using the chosen displacement. The wind force, according to the height, differs for each design code. In Section 4.4, we compare the shear forces and moments obtained by the design codes and those by the equivalent static wind forces based on the measured dynamic displacement in the wind tunnel test.

4.4. Shear Forces and Moments. The shear forces and moments of the Busan tower were calculated using the wind loads obtained in the previous section. Similarly, comparative test values were evaluated using the equivalent static wind forces.

Figure 16 shows the shear force and moment of the Busan tower. The magnitudes of the base shear forces were in the order of KBC2009 > EUROCODE > AIJ2004 > ASCE7-10.
The base overturning moments were in the order of KBC2009 > AIJ2004 $\approx$ EUROCODE $>$ ASCE7-10. The base shear and moment prescribed by KBC2009 exceeded those of other design codes owing to the design wind velocity being multiplied by the importance factor of 1.1.

Table 4 compares the shear forces and moments corresponding to the basic wind velocity of $40 \mathrm{~m} / \mathrm{s}$. The $3 \mathrm{~s}$ gust in ASCE7 was converted to 10 minutes average speed using the Durst Curve. In terms of the ratios between the design values and experimental value, the shear force is 1.07-1.53, and the moment is $0.90-1.30$. The design wind velocity at $120 \mathrm{~m}$ high differs for each design code and experimental value. If the design wind speed is high, the wind load is also high. The shear force and moment prescribed by EUROCODE and AIJ2004, which have similar wind velocity at $120 \mathrm{~m}$ to that of the wind tunnel test, are similar to the experimental values. However, the high design wind velocity at $120 \mathrm{~m}$ in $\mathrm{KBC} 2009$ results in a higher shear force and moment, whereas the low design wind velocity at $120 \mathrm{~m}$ in ASCE7-10 reveals a lower shear force and moment. Compared to the experimental values, the base shear force prescribed by KBC2009 was 1.53 times, and the moment was 1.3 times the experimental value, which had the highest safety factor. The shear forces and moments calculated using each design code are considered to have reasonable safety factors because they are greater than the experimental 


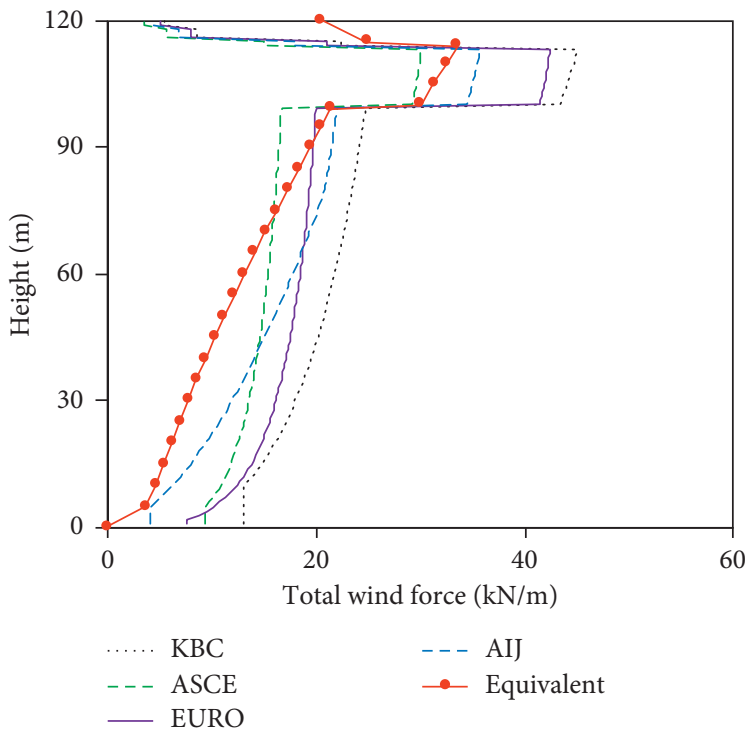

FIGURE 15: Along-wind forces evaluated using design codes and aeroelastic test-based equivalent approach.

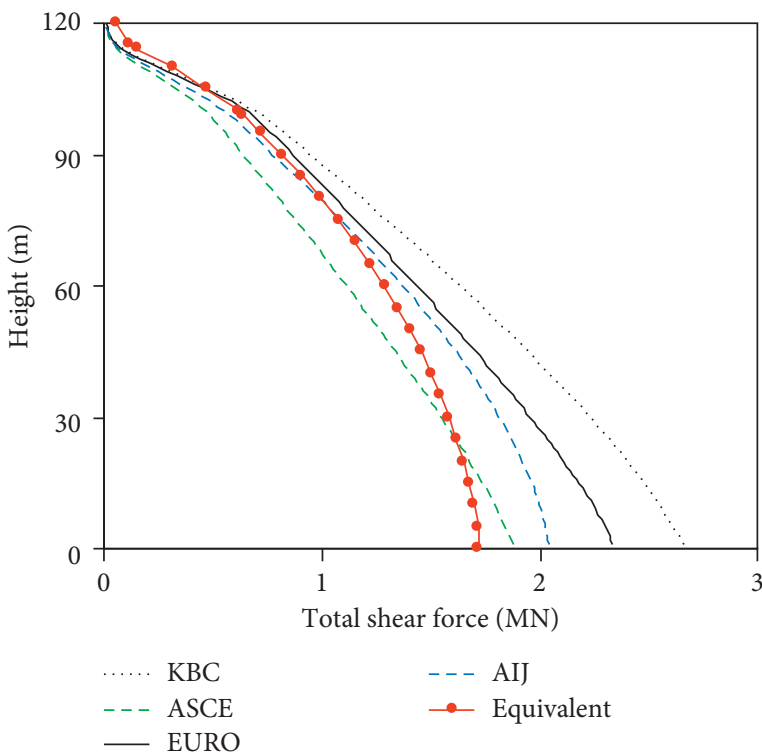

(a)

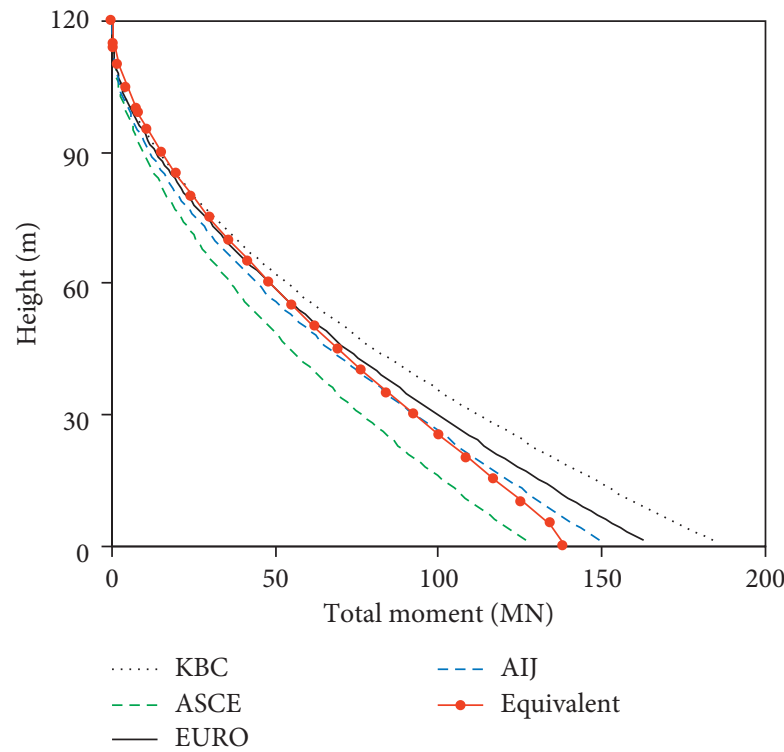

(b)

FIGURE 16: Along-wind shear forces and moments evaluated using design codes and aeroelastic test-based equivalent approach. (a) Shear force. (b) Moment.

values. The base moment prescribed by ASCE7 is slightly lower than the experimental value, but it is not a strict comparison, owing to the difference in the average time.

Figure 17 shows the shear force and moment according to wind velocity at $120 \mathrm{~m}$. In the figure, the solid line is the value obtained from the equivalent static load, and the symbol is the value corresponding to each design wind velocity. As shown in the figure, the values prescribed by EUROCODE and AIJ2004 matched the experimental values best, and the moment prescribed by KBC2009 was slightly lower than the experimental values. The base shear force and moment differ in each design code owing to different design wind velocities. However, the shear force and moment from the codes are generally consistent with the experimental values.

4.5. Maximum Displacements. When the wind load is calculated in accordance with the procedure of the design codes, the displacement cannot be obtained using the same 
TABLE 4: Base shear forces and moments at basic wind velocity of $40 \mathrm{~m} / \mathrm{s}$.

\begin{tabular}{lcccccc}
\hline \multicolumn{1}{c}{ Parameter } & & \multicolumn{2}{c}{ Design code } & \multicolumn{2}{c}{ Test-based } \\
& & KBC & ASCE & EURO & AIJ & 40.0 \\
\multirow{2}{*}{10 min average wind velocity $(\mathrm{m} / \mathrm{s})$} & $10 \mathrm{~m}$ & 40.0 & 40.0 & 40.0 & 40.0 \\
& $120 \mathrm{~m}$ & 64.1 & 52.0 & 59.2 & 57.9 & 58.1 \\
\hline \multirow{2}{*}{ Base shear force } & $\mathrm{MN}$ & 2.67 & 1.88 & 2.22 & 2.04 & 1.75 \\
& Code/test & 1.53 & 1.07 & 1.27 & 1.17 & 1.00 \\
\hline \multirow{2}{*}{ Base moment } & MN-m & 183.9 & 126.6 & 148.9 & 149.4 & 141.2 \\
& Code/test & 1.30 & 0.90 & 1.05 & 1.06 & 1.00 \\
\hline
\end{tabular}

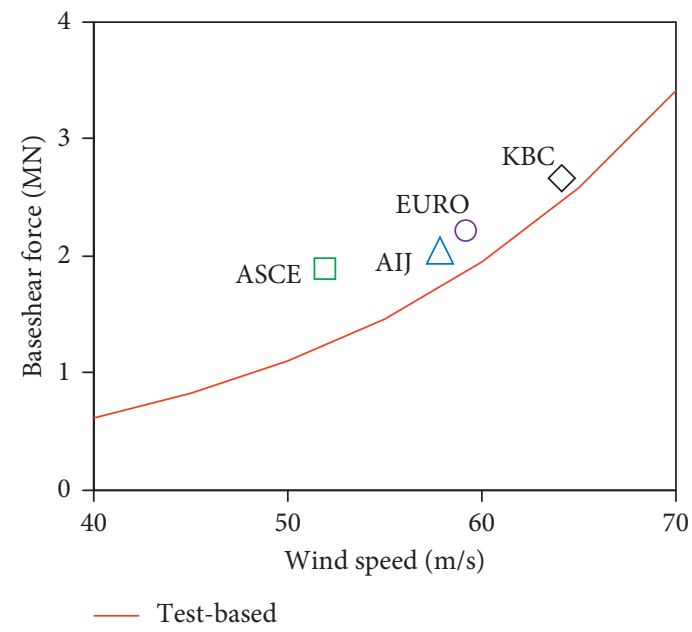

(a)

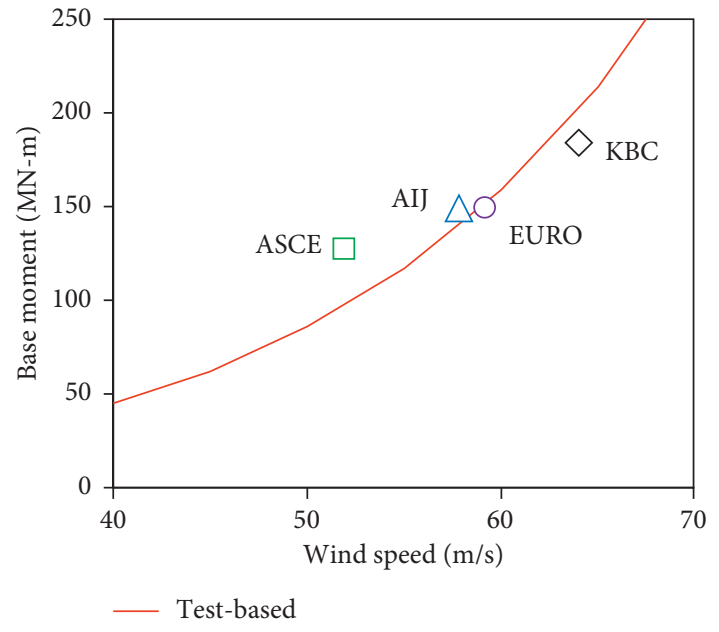

(b)

Figure 17: (a) Base shear forces and (b) base moments vs. wind velocity at $120 \mathrm{~m}$.

TABle 5: Maximum along-wind displacements at basic wind velocity of $40 \mathrm{~m} / \mathrm{s}$.

\begin{tabular}{|c|c|c|c|c|c|}
\hline Design code & KBC & ASCE & EURO & AIJ & Test \\
\hline 10 minute average design wind velocity $(\mathrm{m} / \mathrm{s})$ & 64.1 & 52.0 & 59.2 & 57.9 & 58.1 \\
\hline Displacement (m) & 0.537 & 0.358 & 0.423 & 0.457 & 0.388 \\
\hline Code/test & 1.38 & 0.92 & 1.09 & 1.18 & 1.00 \\
\hline
\end{tabular}

means. Hence, to calculate the displacement, the wind forces in Figure 15 were applied to the ANSYS structural analysis model in Figure 5. Table 5 compares the maximum displacement corresponding to the basic wind velocity of $40 \mathrm{~m} /$ s. In this case, the displacement prescribed by EUROCODE, with a design wind velocity similar to the wind tunnel test, is most similar to the experimental value. Additionally, the displacement prescribed by KBC2009 with high design wind velocity was the largest.

Figure 18 compares the maximum displacement of the along-wind direction obtained in the structural analysis and the aeroelastic wind tunnel test. The displacement of each design code is in good agreement with the results of the test. The magnitude of the maximum displacement is in the order of $\mathrm{KBC}>$ EUROCODE $>$ AIJ $>$ ASCE7. The design wind velocity for each standard differs, and the magnitude of the maximum displacement differs accordingly. However, as shown in the figure, the measured and code-based displacements increase consistently with the wind velocity. Each design code can predict the maximum displacement of the tower well and has a similar safety margin for each design wind velocity. 


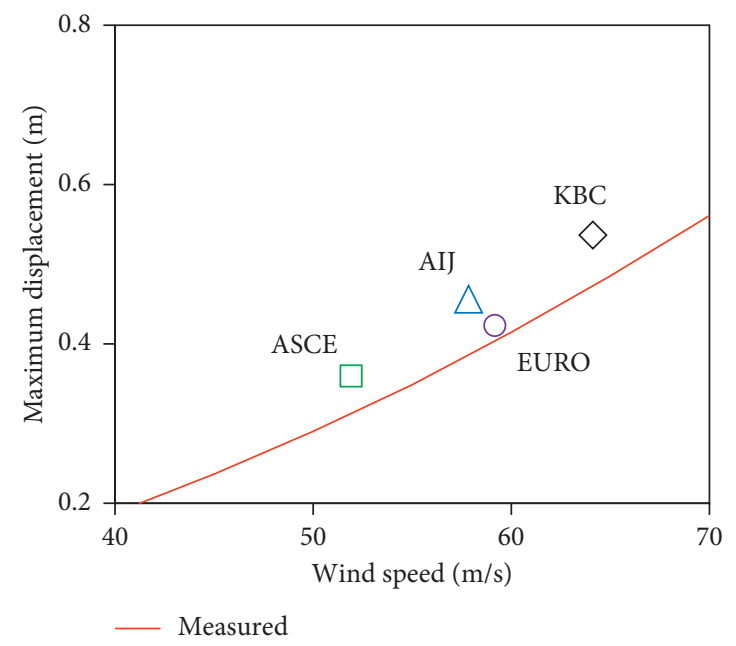

FiguRE 18: Maximum along-wind displacements by aeroelastic wind tunnel test and code-based structural analysis.

\section{Conclusions}

This study compared the wind loads and responses obtained from four design codes-KBC2009 (Korea), ASCE7-10 (USA), EUROCODE (Europe), and AIJ2004 (Japan)—with the results of wind tunnel tests of the Busan tower. The following results were obtained:

(i) Based on the short-term measurements of the ambient accelerations at the Busan tower, the identified natural frequency and damping ratio of the fundamental mode were, respectively, $0.242 \mathrm{~Hz}$ and $1.0 \%$ through the FDD method. Accordingly, these data validated the structural analysis model and aeroelastic wind tunnel model of the tower.

(ii) The height correction factors for wind profile are in the range of 1.45 to 1.48 , and the gust effect factors are 2.40 to 2.65 in the KBC, EUROCODE, and AIJ. Although the basic wind speed was the same, the design wind speeds were different in the height correction process and were in the range of $52.0-64.1 \mathrm{~m} / \mathrm{s}$.

(iii) The magnitudes of the base shear forces, calculated by each design code, were in the order of $\mathrm{KBC}>$ EUROCODE $>$ AIJ $>$ ASCE, while the base moments were in the order of $\mathrm{KBC}>\mathrm{AIJ} \approx \mathrm{EUROCODE}>\mathrm{ASCE}$. The results of the $\mathrm{KBC}$ code are greater than those of the other codes as an importance factor is applied for nonresidential high-rise towers, thereby increasing the design wind velocity by $10 \%$.

(iv) In terms of the ratios between the design values and experimental value, the base shear forces were in the range of 1.07-1.53, and the moments were in the range of $0.90-1.30$. The shear forces and moments calculated from each design code were considered to have reasonable safety factors as most of these were greater than the experimental values. (v) The maximum displacements obtained from each design code were in satisfactory agreement with the aeroelastic model test. In particular, the values of EUROCODE and AIJ2004 agreed well with the experimental values. The maximum displacement was $\mathrm{KBC}>$ EUROCODE $>$ AIJ $>$ ASCE.

In conclusion, each design code reasonably estimated the wind forces and the responses of the tower and seemed to have an appropriate safety margin. The scatter in the predicted wind loads arose primarily from the variations in the definition of design wind velocity in the respective design codes.

\section{Data Availability}

The data used to support the findings of this study are available from the corresponding author upon request.

\section{Conflicts of Interest}

The authors declare that they have no conflicts of interest.

\section{Acknowledgments}

This research was supported by Basic Science Research Program through the National Research Foundation of Korea (NRF) and funded by the Ministry of Science, ICT \& Future Planning (no. NRF-2019R1I1A3A01063222).

\section{References}

[1] W. Jesien, T. Stathopoulos, and H. K. Ha, "Dynamic alongwind response of buildings: comparative study," Journal of Structural Engineering, ASCE, vol. 119, no. 5, pp. 1498-1515, 1993.

[2] G. Solari, "Turbulence modeling for gust loading," Journal of Structural Engineering, vol. 113, no. 7, pp. 1550-1569, 1987.

[3] E. Simiu, "Revised procedure for estimating along-wind response," Journal of the Structural Division, vol. 106, no. 1, pp. 1-10, 1980. 
[4] D. Lungu, P. Van Gelder, and R. Trandafir, Comparative Study of Eurocode 1, ISO and ASCE Procedures for Calculating Wind Loads, Technical University, Delft, Netherlands, 1996.

[5] T. Kijewski and A. Kareem, "Dynamic wind effects: a comparative study of provisions in codes and standards with wind tunnel data," Wind and Structures, vol. 1, no. 1, pp. 77-109, 1998.

[6] Y. Zhou, T. Kijewski, and A. Kareem, "Along-wind load effects on tall buildings: comparative study of major international codes and standards," Journal of Structural Engineering, vol. 128, no. 6, pp. 788-796, 2002.

[7] D. K. Kwon and A. Kareem, "Comparative study of major international wind codes and standards for wind effects on tall buildings," Engineering Structures, vol. 51, pp. 23-35, 2013.

[8] A. A. Badri, M. M. Hussein, and W. A. Attia, "Study of wind tunnel test results of high-rise buildings compared to different design codes," Wind and Structures, vol. 20, no. 5, pp. 623-642, 2015.

[9] J. Holmes, Y. Tamura, and P. Krishna, "Comparison of wind loads calculated by fifteen different codes and standards, for low, medium and high-rise buildings," in Proceedings of the 11th American Conference on Wind Engineering, San Juan, Puerto Rico, 2009.

[10] R. Bashor and A. Kareem, "Comparative Study of Major International Standards," in Proceedings of the 7th Asia-Pacific Conference on Wind Engineering, Taipei, China, 2009.

[11] European Committee for Standardization, Eurocode 1: Action on Structures-General Actions-Part 1-4: Wind Action, European Standard, 1991, European Committee for Standardization, Brussels, Belgium, 2010.

[12] American Society of Civil Engineers, Minimum Design Loads for Buildings and other Structures, ASCE Standard ASCE/SEI 7-10, American Society of Civil Engineers, Reston, VI, USA, 2010.

[13] Architectural Institute of Japan, AIJ Recommendations for Loads on Buildings, Architectural Institute of Japan, Tokyo, Japan, 2014.

[14] Architectural Institute of Korea, Korean Building Code $(K B C)$, Architectural Institute of Korea, Seoul, South Korea, 2009.

[15] R. Brincker, L. Zhang, and P. Andersen, "Modal identification of output-only systems using frequency domain decomposition," Smart Materials and Structures, vol. 10, no. 3, pp. 441-445, 2001.

[16] Y. Tamura, L. Zhang, A. Yoshida, S. Nakata, and T. Itoh, Ambient Vibration Tests and Modal Identification of Structures by FDD and 2dof-RD Technique, Structural Engineers World Congress, Yokohama, Japan, 2002.

[17] ANSYS, https://www.ansys.com/products/structures.

[18] MIDAS, https://www.midasoft.com.

[19] R. L. Schwiesow and R. S. Lawrence, "Effects of a change of terrain height and roughness on a wind profile," BoundaryLayer Meteorology, vol. 22, no. 1, pp. 109-122, 1982.

[20] Y. Nakamura and Y. Tomonari, "The effects of surface roughness on the flow past circular cylinders at high Reynolds numbers," Journal of Fluid Mechanics, vol. 123, pp. 363-378, 1982.

[21] C.-H. Chen, C.-H. Chang, and Y.-Y. Lin, "The influence of model surface roughness on wind loads of the RC chimney by comparing the full-scale measurements and wind tunnel simulations," Wind and Structures An International Journal, vol. 16, no. 2, pp. 137-156, 2013.

[22] S. Liang, W. Yang, J. Song, L. Wang, and G. Hu, "Windinduced responses of a tall chimney by aeroelastic wind tunnel test using a continuous model," Engineering Structures, vol. 176, pp. 871-880, 2018.

[23] M. Liu, S. Y. Li, H. X. Li, S. K. Li, and Z. Q. Chen, "Reynolds number effects on wind-induced responses of a $243 \mathrm{~m}$-high solar tower in elastic wind tunnel tests," Journal of Aerospace Engineering, ASCE, vol. 32, no. 4, 2019.

[24] M. Kasperski and H.-J. Niemann, "The L.R.C. (load-responsecorrelation)-method a general method of estimating unfavourable wind load distributions for linear and nonlinear structural behaviour," Journal of Wind Engineering and Industrial Aerodynamics, vol. 43, no. 1-3, pp. 1753-1763, 1992.

[25] X. Chen and A. Kareem, "Equivalent static wind loads for buffeting response of bridges," Journal of Structural Engineering, ASCE, vol. 127, no. 12, 2001.

[26] J. D. Holmes, "Effective static load distributions in wind engineering," Journal of Wind Engineering and Industrial Aerodynamics, vol. 90, no. 2, pp. 1467-1475, 2002.

[27] G. Solari and A. Kareem, "On the formulation of ASCE7-95 gust effect factor," Journal of Wind Engineering and Industrial Aerodynamics, vol. 77, pp. 673-684, 1998.

[28] Y. Zhou, A. Kareem, and M. Gu, "Gust loading factors for design applications," in Proceedings of the 10th International Conference on Wind Engineering, Copenhagen, Denmark, 1999. 